\title{
Perioperative posterior reversible encephalopathy syndrome in a patient with no history of hypertension: a case report
}

\author{
Nobuo Sato ${ }^{1,3^{*}} \mathbb{D}$, Haruhiko Machida ${ }^{2}$, Mitsuharu Kodaka ${ }^{1}$, Keiko Nishiyama ${ }^{1}$ and Makiko Komori ${ }^{1}$
}

\begin{abstract}
Background: Posterior reversible encephalopathy syndrome is characterized by reversible neurological symptoms with leukoencephalopathy detectable by computed tomography (CT) and magnetic resonance (MR) imaging.

Case presentation: We here present a patient with no history of hypertension who, after being transferred back to the ward after undergoing total hysterectomy under general anesthesia, had several seizures and lost consciousness. Posterior reversible encephalopathy syndrome was suspected on the basis of brain CT images and clinical findings. She was treated with respiratory support, sedative drugs, and anticonvulsants, and MR imaging confirmed a diagnosis of posterior reversible encephalopathy syndrome. She regained consciousness and responsiveness the following day.

Conclusions: Clinically, posterior reversible encephalopathy syndrome resembles cerebral infarction or intracranial hemorrhage; MR imaging is useful for differentiating it from these conditions. Including this condition in the differential diagnosis and instituting appropriate treatment is important in minimizing the risk of development of irreversible neurological damage during the perioperative period.
\end{abstract}

Keywords: Posterior reversible encephalopathy syndrome, Total hysterectomy, Hypertension, Postoperative pain management, Unconsciousness, Hypoxemia

\section{Background}

Posterior reversible encephalopathy syndrome (PRES) is a neurological disorder with unique brain computed tomographic (CT) and magnetic resonance (MR) imaging findings [1]. A group of diseases with similar clinical courses and neuro-radiological findings, PRES is characterized by headache, altered mental functioning, seizures, loss of vision, and, typically, hypertension [1, 2]. Reports of PRES have been published increasingly frequently in recent years; however, there are few reports of PRES associated with general anesthesia [3-7], the syndrome having various causes.

We here describe a patient with no history of hypertension who progressively lost consciousness and had

\footnotetext{
* Correspondence: nsato@anes.twmu.ac.jp

1 Department of Anesthesiology, Tokyo Women's Medical University Medical Center East, 2-1-10, Nishi-ogu, Arakawa-ku, Tokyo 116-8567, Japan

${ }^{3}$ Present address: Department of Anesthesiology, Tokyo Women's Medical

University, 8-1, Kawada-cho, Shinjuku-ku, Tokyo 162-8666, Japan

Full list of author information is available at the end of the article
}

several seizures after general anesthesia. She recovered with appropriate treatment in the intensive care unit (ICU) after the diagnosis of PRES had been made from clinical and MRI findings.

\section{Case presentation}

A 46-year-old woman presented to our hospital because of general fatigue. Blood counts showed severe anemia (serum hemoglobin $=2.8 \mathrm{~g} / \mathrm{dL}$ ) and pelvic MR imaging revealed multiple uterine leiomyomas. Otherwise, her physical examination, laboratory tests including blood electrolytes, renal and liver function tests, pulmonary function tests, chest radiographs, electrocardiogram, and transthoracic echocardiography were within normal limits. Her anemia was treated with ferritin and her hemoglobin increased to $11.0 \mathrm{~g} / \mathrm{dL}$ within 2 months. Total hysterectomy under general anesthesia was scheduled for her uterine leiomyomas. On admission, her body weight was $61 \mathrm{~kg}$, height $1.54 \mathrm{~m}$, blood pressure 
(BP) 106/64 mmHg, and heart rate 78 beats/minute. She had no history of hypertension.

Prior to surgery, she received $0.5 \mathrm{mg}$ of atropine and $2 \mathrm{mg}$ of midazolam intramuscularly. In the operation room, she was monitored by electrocardiography, noninvasive arterial $\mathrm{BP}$ measurements, and a pulse oximeter. Her BP was 161/76 mmHg and heart rate 75 beats/minute before induction of general anesthesia, which was induced with propofol, remifentanil, and rocuronium. Following tracheal intubation, she was ventilated with $50 \%$ oxygen and $50 \%$ nitrous oxide and sevoflurane, and intermittent doses of fentanyl (total $0.2 \mathrm{mg}$ ) were administered intravenously. The operation was uneventful, lasting $1 \mathrm{~h}$ and $56 \mathrm{~min}$. Postoperatively, she regained full consciousness and complained of wound pain after extubation. Postoperatively, pain control was achieved with intravenous fentanyl (total $0.2 \mathrm{mg}$ ), and she was transferred to the ward.

After her transfer to the ward, $30 \mathrm{mg}$ of pentazocine hydrochloride and $50 \mathrm{mg}$ of hydroxyzine pamoate were administered intravenously in response to further complaints of wound pain. Her BP ranged between 146/84 and $166 / 100 \mathrm{mmHg}$ in the ward. Two hours after she had been transferred to the ward, she became less responsive; $4 \mathrm{~h}$ later she had six episodes of tonic-clonic seizures lasting from $30 \mathrm{~s}$ to $2 \mathrm{~min}$ and lost consciousness. She was given $5 \mathrm{mg}$ of diazepam intravenously; this terminated the seizures. Even though she was receiving $10 \mathrm{~L} /$ minute oxygen by face mask her oxygen saturation remained low at $90 \%$, she was therefore admitted to the ICU. On admission to the ICU, her Glasgow coma scale was $6 / 15$ (motor 3 , eyes 2 , verbal 1 ). Her respiration was labored with a rate of 18 per minute and stridor, suggesting upper airway obstruction. Her BP was 112/60 mmHg, heart rate 102 beats/minute, body temperature $36.7^{\circ} \mathrm{C}$, and her pupils were $2.5 \mathrm{~mm}$ in diameter, equal, and reactive. Initial arterial blood gas analysis while receiving $12 \mathrm{~L} /$ minute oxygen administered by a face mask showed a $\mathrm{pH}$ of 7.19, $\mathrm{PaCO}_{2}$ of $46 \mathrm{mmHg}, \mathrm{PaO}_{2}$ of $125 \mathrm{mmHg}, \mathrm{HCO}_{3}^{-}$of $17.6 \mathrm{mmol} / \mathrm{L}$, and standard base excess of $-10.6 \mathrm{mmol} / \mathrm{L}$. A chest radiograph showed diffuse, slightly increased opacity in both lungs. Brain CT images taken an hour after the seizures occurred showed symmetrical, slightly hypodense areas predominantly in the subcortical white matter of both occipital lobes.

Based on the aforementioned clinical features and neuroradiological findings, PRES was suspected. The patient was intubated and received mechanical ventilator support while being sedated with midazolam and fentanyl. By $20 \mathrm{~min}$ after intubation, her acidosis had improved dramatically, her arterial blood $\mathrm{pH}$ being 7.43. To prevent seizures, $250 \mathrm{mg}$ of phenytoin and $800 \mathrm{mg}$ of valproate per day were administered. Phenytoin was administered until the fourth and valproate until the 20th day after the event. On the day after admission to the ICU, the $\mathrm{PaO}_{2} / \mathrm{FiO}_{2}$ ratio was over 500. On brain MR imaging performed $15 \mathrm{~h}$ after the seizures had occurred, T2- and diffusion-weighted images revealed symmetrical, increased signal intensity in both parietooccipital lobes (Fig. 1a, b). The lesions showed increased signal intensity on apparent diffusion coefficient map images (Fig. 1c). MR angiography was not suggestive of atherosclerotic changes. After stopping sedation, she regained consciousness and was extubated. She was found to have no neurological deficit except for visual disturbance with hand motion. Her vision had recovered fully by the fourth postoperative day and she was transferred to the ward on the sixth postoperative day. All abnormal findings on brain MR imaging had completely resolved 7 weeks after surgery (Fig. 2a, b and c).

\section{Discussion}

In 1996, the term PRES was proposed for reversible posterior leukoencephalopathy syndrome (RPLS) [1]. The most common causes of PRES/RPLS are hypertensive encephalopathy, preeclampsia/eclampsia, cyclosporin A neurotoxicity, and uremic encephalopathy [1]. Most patients are markedly hypertensive on presentation; however, some have only mildly increased or even normal blood pressure $[8,9]$. In PRES/RPLS, T2-weighted MR
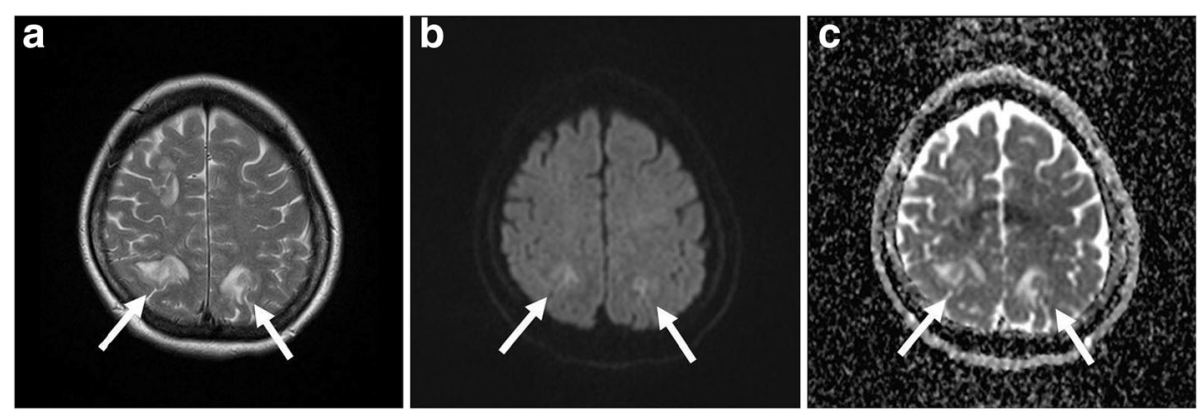

Fig. 1 T2-weighted (a) and diffusion-weighted (b) magnetic resonance images 10 hours after presentation show increased signal intensity in both parietooccipital lobes (arrows). The lesions also show increased signal intensity on apparent diffusion coefficient map images (arrows) (c) 

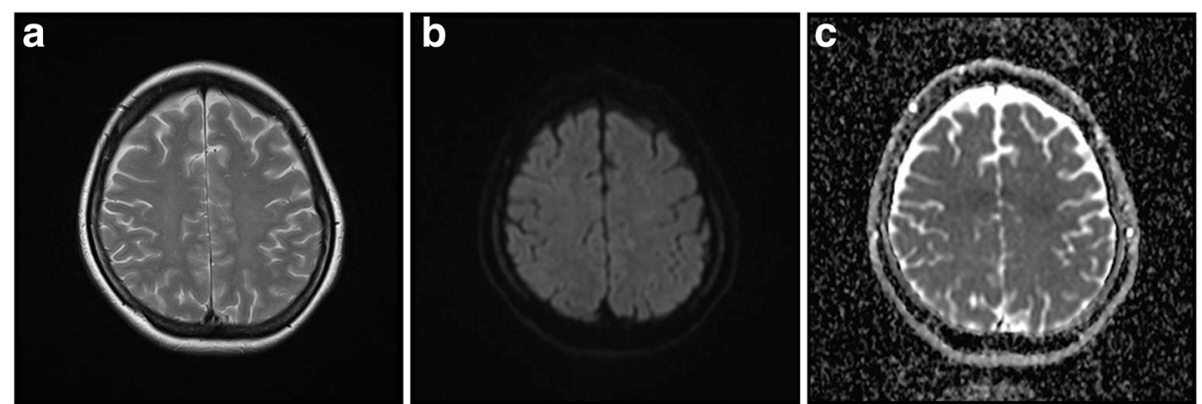

Fig. 2 Magnetic resonance imaging study 7 weeks postoperatively shows resolution of all the lesions in T2-weighted (a), diffusion-weighted (b), and apparent diffusion coefficient map images (c)

imaging characteristically shows hyperintensity spreading out from the parietooccipital regions $[1,2]$. In the acute phase, diffusion-weighted MR imaging can differentiate ischemic injury from conditions known to cause vasogenic brain edema [9-14].

Alterations in hemodynamic state can lead to PRES. Several reports on PRES associated with general anesthesia have been published [3-7]. Although there are various causes for this syndrome, affected patients typically have hypertension at the time of presentation or a history of hypertension.

In this case, the risk factor for PRES was the sustained hypertension caused by incomplete postoperative pain control [15]. Adequate pain control may have prevented the development of PRES. To prevent PRES, all surgery patients undergoing general anesthesia, including low risk patients undergoing low risk surgery, should be admitted to a postanesthetic care unit for frequent checking of vital signs and to receive adequate postoperative pain control [16].

This clinical report underscores the need to check vital signs carefully to ensure early detection of loss of consciousness that could lead to PRES, even when there is no history of hypertension.

The acquisition of MR images was very useful for the early diagnosis of PRES in this case. Brain MRI is much more sensitive than CT [17]; however CT is sometimes preferable for diagnosing PRES in critically ill patients. The combination of the patient's clinical features and MR imaging findings led to early and successful treatment.

\section{Conclusion}

We here report the rare complication of delayed postoperative hypertensive encephalopathy. The diagnosis of PRES was made early and appropriate intensive care management of the patient's symptoms instituted, resulting in complete recovery with no complications.

\section{Abbreviations}

BP: Blood pressure; CT: Computed tomography; ICU: Intensive Care Unit; MR: Magnetic resonance; PRES: Posterior reversible encephalopathy syndrome; RPLS: Reversible posterior leukoencephalopathy syndrome

\section{Authors' contributions}

NS drafted the manuscript. NS, HM, MiK, KN, and MaK treated the patient, and $\mathrm{HM}, \mathrm{MiK}, \mathrm{KN}$, and MaK helped draft the manuscript and revise it critically. All authors read and approved the final manuscript

\section{Competing interests}

The authors declare that they have no competing interests.

\section{Consent for publication}

The patient gave written informed consent for publication of this case report and all accompanying images. A copy of the consent form is available for review by the Editor-in-Chief.

\section{Author details}

1Department of Anesthesiology, Tokyo Women's Medical University Medical Center East, 2-1-10, Nishi-ogu, Arakawa-ku, Tokyo 116-8567, Japan.

2Department of Radiology, Tokyo Women's Medical University Medical Center East, Tokyo, Japan. ${ }^{3}$ Present address: Department of Anesthesiology, Tokyo Women's Medical University, 8-1, Kawada-cho, Shinjuku-ku, Tokyo 162-8666, Japan.

Received: 15 September 2016 Accepted: 15 November 2016 Published online: 21 November 2016

\section{References}

1. Hinchey J, Chaves C, Appignani B, Breen J, Pao L, Wang A, et al. A reversible posterior leukoencephalopathy syndrome. N Engl J Med. 1996;334(8):494-500.

2. Casey SO, Sampaio RC, Michel E, Truwit CL. Posterior reversible encephalopathy syndrome: utility of fluid-attenuated inversion recovery MR imaging in the detection of cortical and subcortical lesions. AJNR Am J Neuroradiol. 2000;21(7): 1199-206.

3. Inoue $\mathrm{S}$, Kawaguchi M, Furuya $\mathrm{H}$. A case of posterior reversible encephalopathy syndrome after emergence from anesthesia. J Anesth. 2012;26(1):111-4.

4. Eran A, Barak M. Posterior reversible encephalopathy syndrome after combined general and spinal anesthesia with intrathecal morphine. Anesth Analg. 2009;108(2):609-12.

5. Gharabawy R, Pothula VR, Rubinshteyn V, Silverberg M, Gave AA. Epinephrine-induced posterior reversible encephalopathy syndrome: a case report. J Clin Anesth. 2011;23(6):505-7.

6. Barbara DW, Smith BC, Onigkeit JA. Posterior reversible encephalopathy syndrome as a cause of postoperative blindness. Anesthesiology. 2012; 116(2):472.

7. Yi JH, Ha SH, Kim YK, Choi EM. Posterior reversible encephalopathy syndrome in an untreated hypertensive patient after spinal surgery under general anesthesia -a case report-. Korean J Anesthesiol. 2011;60(5):369-72. 
8. Bartynski WS, Boardman JF, Zeigler ZR, Shadduck RK, Lister J. Posterior reversible encephalopathy syndrome in infection, sepsis, and shock. AJNR Am J Neuroradiol. 2006;27(10):2179-90.

9. Ay H, Buonanno FS, Schaefer PW, Le DA, Wang B, Gonzalez RG, et al. Posterior leukoencephalopathy without severe hypertension: utility of diffusion-weighted MRI. Neurology. 1998;51(5):1369-76.

10. Covarrubias DJ, Luetmer PH, Campeau NG. Posterior reversible encephalopathy syndrome: prognostic utility of quantitative diffusionweighted MR images. AJNR Am J Neuroradiol. 2002;23(6):1038-48.

11. Koch S, Rabinstein A, Falcone S, Forteza A. Diffusion-weighted imaging shows cytotoxic and vasogenic edema in eclampsia. AJNR Am J Neuroradiol. 2001; 22(6):1068-70.

12. Mukherjee P, McKinstry RC. Reversible posterior leukoencephalopathy syndrome: evaluation with diffusion-tensor MR imaging. Radiology. 2001; 219(3):756-65.

13. Provenzale JM, Petrella JR, Cruz LC, Wong JC, Engelter S, Barboriak DP. Quantitative assessment of diffusion abnormalities in posterior reversible encephalopathy syndrome. AJNR Am J Neuroradiol. 2001;22(8):1455-61.

14. Schaefer PW, Buonanno FS, Gonzalez RG, Schwamm LH. Diffusion-weighted imaging discriminates between cytotoxic and vasogenic edema in a patient with eclampsia. Stroke. 1997;28(5):1082-5.

15. Haas CE, LeBlanc JM. Acute postoperative hypertension: a review of therapeutic options. Am J Health Syst Pharm. 2004;61(16):1661-73.

16. Apfelbaum JL, Silverstein JH, Chung FF, Connis RT, Fillmore RB, Hunt SE, et al. Practice guidelines for postanesthetic care: an updated report by the American Society of Anesthesiologists Task Force on Postanesthetic Care. Anesthesiology. 2013;118(2):291-307.

17. Bartynski WS, Boardman JF. Distinct imaging patterns and lesion distribution in posterior reversible encephalopathy syndrome. Am J Neuroradiol. 2007; 28(7):1320-7.

\section{Submit your manuscript to a SpringerOpen ${ }^{\circ}$ journal and benefit from:}

- Convenient online submission

- Rigorous peer review

- Immediate publication on acceptance

- Open access: articles freely available online

- High visibility within the field

- Retaining the copyright to your article 